\title{
Parametric Amplification of Magnetic Resonance Images
}

\author{
R.R.A. Syms, Senior Member, IEEE, T. Floume, I.R. Young, L. Solymar, M. Rea
}

\begin{abstract}
Parametric amplification is considered as a method for detection of magnetic resonance imaging (MRI) signals. The theory of three-frequency amplifiers is reviewed, and aspects relevant to radio-frequency detection are highlighted. The modifications needed for MRI are described, and a parametrically amplified surface coil for $63.85 \mathrm{MHz}$ operation is demonstrated. Electrical characterization is carried out, and good agreement is obtained with theory. A linear gain of 100 (40 dB power gain) and a $Q$-factor of 18,000 are demonstrated. ${ }^{1} \mathrm{H}$ MRI is carried out at $1.5 \mathrm{~T}$ and frequency-domain filtering of images is demonstrated.
\end{abstract}

Index Terms-Parametric amplification, MRI

\section{INTRODUCTION}

$\mathrm{T}$ he steady improvement of magnetic resonance imaging (MRI) owes much to the understanding of factors affecting signal-to-noise ratio [1] and coil filling factors [2]. The quality factors of receive coils are relatively low at room temperature (typically, a few hundred), which conveniently allows short receiver recovery times and avoids the generation of bandwidth artefacts [3]. Image recovery is then by Fourier transformation following low-noise amplification, down-conversion and digital filtering [4]. However, there may be applications for more flexible receivers, for example to minimize the effects of loading in single coils, to improve the uniformity of phased arrays in MR imaging or (in extreme cases) to control bandwidth at the front-end in MR spectroscopy.

This paper considers the application to MRI of parametric amplification, a low-noise technique of considerable interest in the 1960s. The classic description was by Manley and Rowe in 1956 [5], although the principle is much older [6]. Electronic parametric processes involve mixing in a non-linear inductor [7] or capacitor [8]. Many different configurations were investigated, including two-, three- and four-frequency schemes for amplification or frequency conversion $[9,10]$. The most useful is the three-frequency amplifier, which allows

Richard R. A. Syms is with the EEE Dept., Imperial College London, Exhibition Road, London SW7 2AZ, UK (phone: +44-207-594-6203; fax: +44-207-594-6308; e-mail: r.syms@imperial.ac.uk).

Timmy Floume is with the EEE Dept., Imperial College London, Exhibition Road, London SW7 2AZ, UK (email t.floume@imperial.ac.uk).

Ian Young is with the EEE Dept., Imperial College London, London SW7 2AZ, UK (email youngimarl@aol.com).

Laszlo Solymar is with the EEE Dept., Imperial College London, London SW7 2AZ, UK (email laszlo.solymar@hertford.ox.ac.uk).

Marc Rea is with the Dept. of Radiology, Imperial College NHS Trust, Paddington, London, W2 1NY, UK (email marc.rea@imperial.ac.uk). phase-independent amplification $[11,12]$.

Early interest focused on telecommunications [13-15] and radio astronomy [16, 17]. However, despite efforts to increase operating frequencies and bandwidth, the parametric amplifier was displaced by the travelling wave tube. Since then, frequencies have been raised to the optical range [18, 19]. Instrumental applications have also been demonstrated. For example, noise squeezing has been demonstrated using twofrequency amplifiers, based on Josephson junctions [20] and mechanical amplifiers [21]. Parametric amplification has been used in detection of AC magnetic fields [22], radio-frequency travelling-wave magnetic fields [23], electroencephalograph [24] and electron spin resonance [25] signals, and there has been interest in applications in microelectromechanical systems [26-29].

In this paper, controllable amplified detection of MRI signals is demonstrated using a lumped-element threefrequency circuit. Section II describes its operating principles, highlighting the main theoretical aspects relevant to a parametrically amplified detector, but leaving detailed mathematical derivations in an Appendix. Section III describes the construction and testing of an amplified detector operating at $63.85 \mathrm{MHz}$. Section IV presents the results of electrical characterization and ${ }^{1} \mathrm{H}$ MR imaging using a $1.5 \mathrm{~T}$ scanner, and conclusions are presented in Section V.

\section{THEORY}

A conventional amplifier operates by transfer of energy from a direct-current source, using a three-terminal non-linear device in a simple circuit. Its gain is normally flat and its noise factor low. In contrast, a parametric amplifier operates by energy transfer from an alternating source, with a frequency that is much higher than that of the signal. It needs only a twoterminal non-linear reactance, but its circuit configuration is more complicated, and a relatively expensive pump source is required. In addition, some aspects of its performance - gainbandwidth, and noise factor at high frequency - are limited. However, if the bandwidth and frequency are small, neither limitation holds and excellent performance may be obtained. Since this is the case in magnetic resonance imaging, there may be genuine opportunities. However, a parametrically amplified detector for MRI (in contrast to a communications amplifier) must cope with variable loading. Consequently, many features of design and operation are different. Here we review the most relevant aspects, and illustrate their implications with simulations.

\subsection{General arrangement}

Figure 1 shows a three-frequency amplifier, which consists of 
three L-C resonators coupled by a varactor $C_{\mathrm{V}}$, with average capacitance $C_{0}$ and non-linear coefficient $\beta$ (so that $C_{\mathrm{V}}=C_{0}(1$ $+\beta V_{\mathrm{C}}$ ) where $V_{\mathrm{C}}$ is the varactor voltage). The signal (a voltage source $V_{\mathrm{S}}$ with output impedance $R_{\mathrm{SO}}$ ) and the load $R_{\mathrm{L}}$ are located in a signal loop containing a resonator formed by an inductor $L_{\mathrm{S}}$, a capacitor $C_{\mathrm{S}}$, and $C_{0}$. A strong source of pump power (a source $V_{\mathrm{P}}$ with output impedance $R_{\mathrm{PO}}$ ) is located in a pump resonator formed by $L_{\mathrm{P}}, C_{\mathrm{P}}$ and $C_{0}$. Also present is an idler resonator formed from $L_{\mathrm{I}}, C_{\mathrm{I}}$ and $C_{0} . R_{\mathrm{C}}, R_{\mathrm{S}}, R_{\mathrm{P}}$ and $R_{\mathrm{I}}$ are resistances associated with $C_{\mathrm{V}}, L_{\mathrm{S}}, L_{\mathrm{P}}$ and $L_{\mathrm{I}}$, respectively. The signal loop is resonant at angular frequency $\omega_{\mathrm{S} 0}$, and the pump and idler loops at $\omega_{\mathrm{P} 0}$ and $\omega_{\mathrm{I} 0}$. The loop currents are $I_{\mathrm{S}}$, $I_{\mathrm{P}}$ and $I_{\mathrm{I}}$, and oscillate at $\omega_{\mathrm{S}}, \omega_{\mathrm{P}}$ and $\omega_{\mathrm{I}}$ near $\omega_{\mathrm{S} 0}, \omega_{\mathrm{P} 0}$ and $\omega_{\mathrm{I} 0}$. If the circuit parameters are suitable, each current will mainly circulate in its own loop. Amplification is achieved through two-step mixing in the varactor. In the first step, the signal is mixed with the pump to create an idler at the difference frequency $\omega_{\mathrm{I}}=\omega_{\mathrm{P}}-\omega_{\mathrm{S}}$. In the second, the idler is mixed with the pump to create further signal, in-phase with the original.

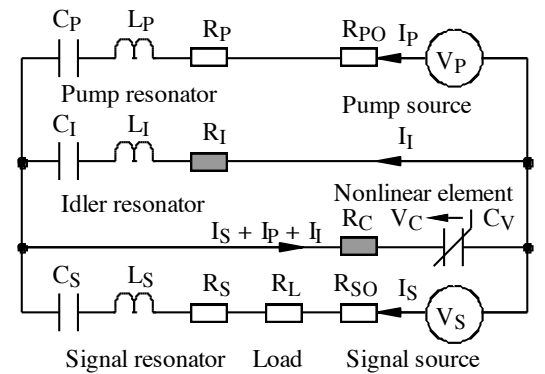

Fig. 1. Equivalent circuit of a three-frequency amplifier. Shaded components indicate Johnson noise sources additional to those in a simple resonator.

\subsection{Analysis}

The circuit can be analysed as detailed in the Appendix. The main assumptions are that the voltage amplitudes $v_{\mathrm{S}}, v_{\mathrm{P}}$ and $v_{\mathrm{I}}$ at frequencies $\omega_{\mathrm{S}}, \omega_{\mathrm{P}}$ and $\omega_{\mathrm{I}}$ are complex, that the varactor voltage contains terms at all three frequencies, and the pump voltage is much greater than the signal and idler voltages. If the system is matched, the overall voltage gain $G$ can be found as the product $G \approx G_{\mathrm{C}} G_{\mathrm{A}}$, where $G_{\mathrm{C}}$ and $G_{\mathrm{A}}$ are the gains of the passive coil and the additional parametric process. Here, we focus mainly on the additional parametric gain $G_{\mathrm{A}}$ (which is much larger and faster varying than $G_{\mathrm{C}}$ ) and its dependence on operating parameters and loading.

\subsection{Gain and bandwidth}

If the circuit is set up correctly, the signal resonator will be tuned so that $\omega_{\mathrm{s} 00}$ is the angular frequency for detection, and the pump resonator so that $\omega_{\mathrm{P} 00}=\omega_{\mathrm{S} 00}+\omega_{\mathrm{I} 00}$, where $\omega_{\mathrm{I} 00}$ is fixed but arbitrary. If the signal and pump are also both onresonance, the amplifier gain reduces to the peak value (Equation A12 in the Appendix):

$$
G_{\mathrm{A} 0} \approx 1 /(1-k)
$$

Here $k$ is the pumping parameter, given by (A9):

$$
k \approx \beta^{2} v_{\mathrm{P}} v_{\mathrm{P}}^{*} /\left(\omega_{\mathrm{S} 0} \omega_{\mathrm{I} 0} \omega_{\mathrm{P} 0}^{2} C_{0}^{4} R_{\mathrm{S}} R_{\mathrm{I}}^{\prime} R_{\mathrm{P}}^{\prime 2}\right)
$$

This result implies that pumping injects into the signal loop a negative resistance $-R_{\mathrm{A}}=-k R_{\mathrm{S}}$, that can counter losses.
Figure 2 shows the variation of $G_{\mathrm{A} 0}$ with $k$. The gain rises rapidly as $k$ approaches unity, the oscillation threshold. Since $k$ is proportional to $v_{\mathrm{P}} v_{\mathrm{P}} *$, it can be written as $k=P / P_{\text {osc }}$, where $P$ is the pump power and $P_{\text {osc }}$ is the power at oscillation. Since $P_{\text {osc }}$ depends on $R_{\mathrm{S}}$, both the gain and threshold depend on loading, especially at high gain. Circulators were originally used to improve gain stability [30]; however, these are inappropriate for MRI, since they contain magnetized ferrite. Since the pump power needed to achieve a particular gain depends strongly on the loading, a practical amplified detector will require a real-time algorithm to determine the correct operating conditions. For example, the simplest solution to variable loading is to determine the Q-factor of the passive cavity by measuring its ring-down time during pre-scan.

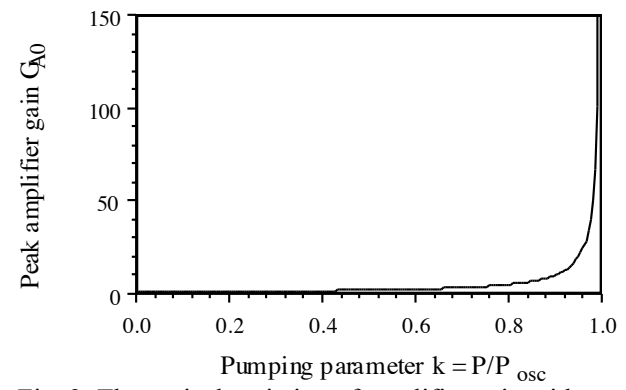

Fig. 2. Theoretical variation of amplifier gain with pumping parameter.

More generally, the resonators will all be tuned correctly, but the signal angular frequency will be off-resonance by an amount $\Delta \omega_{S}$. In this case, the coil, amplifier and overall responses will now all be functions of $\Delta \omega_{\mathrm{S}}$. The coil gain $G_{\mathrm{C}}$ then varies slowly, but $G_{\mathrm{A}}$ varies much more rapidly and dominates the overall response. For high gain, we obtain (by appropriately combining A7 and A11):

$$
G_{\mathrm{A}} \approx 1 /\left\{1-k+\mathrm{j}\left(2 Q_{\mathrm{S}} \Delta \omega_{\mathrm{S}} / \omega_{\mathrm{S} 00}+2 Q_{\mathrm{I}} \Delta \omega_{\mathrm{S}} / \omega_{\mathrm{I} 00}\right)\right\}
$$

Here $Q_{\mathrm{S}}$ and $Q_{\mathrm{I}}$ are the Q-factors of the signal and idler loops, respectively. Curve 1 in Figure 3 shows the variation of $G_{\mathrm{A}}$ with the normalised signal frequency deviation $\Delta w_{\mathrm{S}}=$ $\Delta \omega_{\mathrm{S}} / \omega_{\mathrm{S} 00}$, assuming $k=0.9$ (so that $G_{A 0}=10$ ), $f_{\mathrm{S} 00}=\omega_{\mathrm{S} 00} / 2 \pi=$ $63.85 \mathrm{MHz}, f_{\mathrm{P} 00}=100 \mathrm{MHz}, Q_{\mathrm{S}}=60$ and $Q_{\mathrm{I}}=60$. These parameters are representative of the experimental amplifier described in Section III. Here and throughout, we plot the amplitude modulus of gain, which falls off on either side of a central maximum following a normal resonance curve. Half power is reached when the real and imaginary parts in (3) are equal, allowing the Q-factor to be found as:

$$
Q_{\mathrm{A}}=G_{\mathrm{A} 0}\left(Q_{\mathrm{S}}+Q_{\mathrm{I}} \omega_{\mathrm{S} 00} / \omega_{\mathrm{I} 00}\right)
$$

This result implies that $Q_{\mathrm{A}}$ will rise linearly with $G_{\mathrm{A} 0}$, but will be larger than expected from the Q-factor of the signal circuit alone. Defining the bandwidth of the amplifier as $B=2 \Delta \omega_{\mathrm{S}}$, and those of the signal and idler loops as $B_{\mathrm{S}}=\omega_{\mathrm{S} 00} / Q_{\mathrm{S}}$ and $B_{\mathrm{I}}$ $=\omega_{\mathrm{I} 00} / Q_{\mathrm{I}}$, the gain-bandwidth product may be found as:

$$
G_{\mathrm{A} 0} B=1 /\left(1 / B_{\mathrm{S}}+1 / B_{\mathrm{I}}\right)
$$

This result implies that the bandwidth will be small at high gain, and this represents a key limitation of parametric 
amplifiers; however, circuit modifications can be introduced to increase bandwidth, as described in Section 2.6.

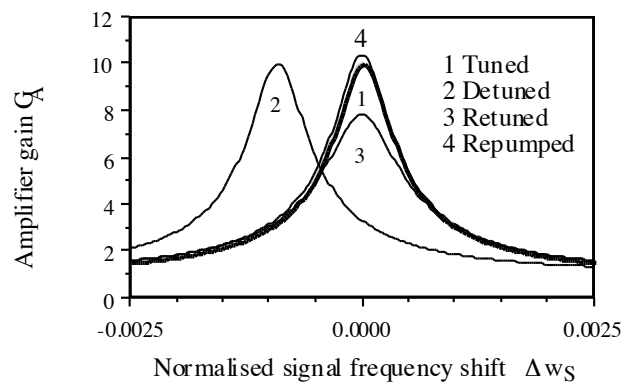

Fig. 3. Theoretical variation of amplifier gain with normalised signal frequency shift, assuming 1) synchronism, 2) detuned signal resonator, 3) retuned pump frequency and 4) increased pump power. Assumed parameter values: $k=0.9, f_{\mathrm{S} 00}=\omega_{\mathrm{S} 00} / 2 \pi=63.85 \mathrm{MHz}, f_{\mathrm{P} 00}=100 \mathrm{MHz}, Q_{\mathrm{S}}=Q_{\mathrm{I}}=60$.

\subsection{Detuning and retuning}

More generally still, the signal resonator may also be detuned by loading, a likely occurrence in MRI. Assuming the change in signal angular resonant frequency is $\Delta \omega_{\mathrm{s} 0}$, the amplifier gain approximates to (A7 and A11):

$$
G_{\mathrm{A}} \approx 1 /\left\{1-k+\mathrm{j}\left[2 Q_{\mathrm{S}}\left(\Delta \omega_{\mathrm{S}}-\Delta \omega_{\mathrm{S} 0}\right) / \omega_{\mathrm{S} 00}+2 Q_{\mathrm{I}} \Delta \omega_{\mathrm{S}} / \omega_{\mathrm{I} 00}\right]\right\}
$$

The gain will be maximum (and restored to $G_{\mathrm{A} 0}$ ) when the imaginary parts above vanish. This condition requires:

$$
\Delta \omega_{\mathrm{S}}=\Delta \omega_{\mathrm{S} 0} /\left(1+Q_{\mathrm{I}} \omega_{\mathrm{S} 00} / Q_{\mathrm{S}} \omega_{\mathrm{I} 00}\right)
$$

Thus, the optimum signal frequency will track any detuning of the signal resonator, but at a rate differing from unity. Curve 2 in Figure 3 shows the response of a detuned amplifier with a normalised signal detuning $\Delta w_{\mathrm{S} 0}=\Delta \omega_{\mathrm{S} 0} / \omega_{\mathrm{S} 00}=-0.0025$, and the same parameters as before. A similar peak gain is achieved, but now at a different frequency.

The effect of signal resonator detuning may be corrected using the pump. Assuming a change $\Delta \omega_{\mathrm{p}}$ in pump angular frequency, the high-gain approximation yields (A7 and A11):

$$
\begin{gathered}
G_{\mathrm{A}} \approx 1 /\left\{1+\left(2 Q_{\mathrm{P}} \Delta \omega_{\mathrm{P}} / \omega_{\mathrm{P} 00}\right)^{2}-k+\mathrm{j}\left[2 Q_{\mathrm{S}}\left(\Delta \omega_{\mathrm{S}}-\Delta \omega_{\mathrm{S} 0}\right) / \omega_{\mathrm{S} 00}-\right.\right. \\
\left.\left.2 Q_{\mathrm{I}}\left(\Delta \omega_{\mathrm{P}}-\Delta \omega_{\mathrm{S}}\right) / \omega_{\mathrm{I} 00}\right]\right\}
\end{gathered}
$$

Here $Q_{\mathrm{P}}$ is the Q-factor of the pump loop. Maximum gain may now be obtained at the original signal frequency if the imaginary parts in (8) vanish at $\Delta \omega_{\mathrm{S}}=0$, which requires a pump frequency shift given by:

$$
\Delta \omega_{\mathrm{P}}=-\Delta \omega_{\mathrm{S} 0}\left(Q_{\mathrm{S}} \omega_{\mathrm{I} 00} / Q_{\mathrm{I}} \omega_{\mathrm{S} 00}\right)
$$

The change in pump frequency needed to retune the amplifier therefore varies linearly with the original detuning. If this change is applied, however, the peak gain will be reduced to:

$$
G_{\mathrm{A} 0}{ }^{\prime} \approx 1 /\left\{1+\left(2 Q_{\mathrm{P}} \Delta \omega_{\mathrm{P}} / \omega_{\mathrm{P} 00}\right)^{2}-k\right\}
$$

Curve 3 in Figure 3 shows the response of the detuned amplifier, after changing $\omega_{\mathrm{P}}$ as above, assuming that $Q_{\mathrm{P}}=100$. As expected, maximum gain now occurs at $\Delta w_{\mathrm{S}}=0$ once again, but the peak gain is reduced. This result implies that any correction made for detuning also requires alteration of the pump power to restore the gain. To do so, $k$ must simply be increased by a factor $k^{\prime}=1+\left(2 Q_{\mathrm{P}} \Delta \omega_{\mathrm{P}} / \omega_{\mathrm{P} 00}\right)^{2} / k$. Curve 4 in Figure 3 shows the response after increasing $k$ this way; the peak gain is now restored. If the detector is tuned and matched for a particular gain in the unloaded state, and then loaded, retuning and making the necessary compensation to the gain will automatically bring it back to the matched condition.

It may of course be that the resonators are tuned correctly, but the gain must be optimized for a different signal frequency (for example, to tune the amplifier to a specific NMR frequency at high gain). If $\Delta \omega_{\mathrm{S}} \neq 0$, the gain now becomes:

$$
\begin{gathered}
G_{\mathrm{A}} \approx 1 /\left\{1+\left(2 Q_{\mathrm{P}} \Delta \omega_{\mathrm{P}} / \omega_{\mathrm{P} 00}\right)^{2}-k+\mathrm{j}\left[2 Q_{\mathrm{S}} \Delta \omega_{\mathrm{S}} / \omega_{\mathrm{S} 00}-2 Q_{\mathrm{I}}\left(\Delta \omega_{\mathrm{P}}-\right.\right.\right. \\
\left.\left.\left.\Delta \omega_{\mathrm{S}}\right) / \omega_{\mathrm{I} 00}\right]\right\}
\end{gathered}
$$

Maximum gain will now be obtained at the new signal frequency, if:

$$
\Delta \omega_{\mathrm{P}}=\Delta \omega_{\mathrm{S}}\left(1+Q_{\mathrm{S}} \omega_{\mathrm{I} 00} / Q_{\mathrm{I}} \omega_{\mathrm{S} 00}\right) .
$$

Once again, the necessary change in pump frequency varies linearly with the desired shift in optimum signal frequency.

\subsection{Noise factor}

Noise in a parametric amplifier arises from two main sources [31, 32]. The first is Johnson noise at the signal frequency, due to resistance in the signal circuit. The second is Johnson noise in the idler circuit, which is mixed with the pump to appear in the signal band. Assuming the whole circuit is at room temperature, the noise factor $F$ is:

$$
F \approx 1+\left(R_{\mathrm{S}}+R_{\mathrm{C}}\right) / R_{\mathrm{S} 0}+\left(\omega_{\mathrm{S} 00} / \omega_{\mathrm{I} 00}\right) R_{\mathrm{A}} / R_{\mathrm{S} 0}
$$

Assuming that the load is mainly matched to the source, $\mathrm{R}_{\mathrm{S} 0} \approx$ $R_{\mathrm{L}}$. Similarly, at high gain, $R_{\mathrm{A}} \approx 2 R_{\mathrm{L}}$. If $F \approx 1$, it may then be written as the product $F=F_{\mathrm{C}} F_{\mathrm{A}}$. Here $F_{\mathrm{C}}$ is the noise factor of the passive coil and $F_{\mathrm{A}}$ that of the amplifier, and:

$$
\begin{gathered}
F_{\mathrm{C}} \approx 1+R_{\mathrm{S}} / R_{\mathrm{L}} \\
F_{\mathrm{A}} \approx 1+R_{\mathrm{C}} / R_{\mathrm{L}}+2 \omega_{\mathrm{S} 00} / \omega_{\mathrm{I} 00}
\end{gathered}
$$

This result implies that additional amplifier noise arises from the shaded noise sources $R_{\mathrm{C}}$ and $R_{\mathrm{I}}$ in Figure 1. $F_{\mathrm{A}}$ will be low if $R_{\mathrm{C}}<<R_{\mathrm{L}}$ and $\omega_{100}>>\omega_{\mathrm{S} 00}$, so high-performance diodes pumped at high frequency yield the best results.

Extremely low noise factors may be obtained. For example, if $R_{\mathrm{C}}$ is ignored completely, $F_{\mathrm{A}} \approx 1.2$ (corresponding to a noise figure of $\left.N F_{\mathrm{A}}=0.8 \mathrm{~dB}\right)$ for $\omega_{\mathrm{I} 00} / \omega_{\mathrm{S} 00}=10$, and $F_{\mathrm{A}} \approx 1.1\left(N F_{\mathrm{A}}\right.$ $=0.4 \mathrm{~dB}$ ) for $\omega_{\mathrm{IO0}} / \omega_{\mathrm{S} 00}=20$. Suitable frequency ratios have been achieved in the past. For example, a $30 \mathrm{MHz}$ hybrid parametric amplifier achieved a noise temperature of $18{ }^{\circ} \mathrm{K}$ and a noise factor of $F_{\mathrm{A}}=1.06$ (corresponding to $N F_{\mathrm{A}}=0.25$ $\mathrm{dB}$ ) at room temperature in 1976, using a pump frequency of $860 \mathrm{MHz}$ so that $\omega_{\mathrm{I} 00} / \omega_{\mathrm{S} 00}=27.7$ [33]. This should be compared with GaAs field effect transistor preamplifiers used for MRI, which have noise figures of 0.4-0.5 dB [34].

Because of the high signal frequencies involved (tens of $\mathrm{GHz}$ ), it was difficult to achieve the necessary frequency 
ratios in communications amplifiers (although pump frequencies were eventually raised to around $100 \mathrm{GHz}$ [35]). Low noise figures were therefore mainly obtained using cryogenic cooling at liquid helium temperatures [36], with limiting noise temperatures of a few degrees $\mathrm{K}$ (for example, $8.5^{\circ} \mathrm{K}$, corresponding to $N F_{\mathrm{A}}=0.12 \mathrm{~dB}$ [37]). Cryogenic cooling could obviously be applied to an amplified detector for MRI. For example, refrigeration of the idler loop (which can be done at some distance from a patient) would largely eliminate idler noise.

\subsection{Broadbanding}

Equation 5 implies the gain bandwidth will be increased if the idler frequency is raised, as required for good noise performance, approaching the limit $G_{\mathrm{A} 0} B=B_{\mathrm{S}}$. In fact, for very high frequency pumping, any effect of the idler and pump loops almost disappears and the amplifier may be represented as a capacitance $C_{0}$, a series resistance $R_{\mathrm{C}}$ and a negative resistance $-R_{\mathrm{A}}$ in the signal loop. This approximation considerably simplifies the analysis of modified circuits.

The gain-bandwidth may then be increased using higher order filters in the signal and/or idler loop [38, 39]. Extremely wide bandwidths were demonstrated in this way, and combined with cryogenic cooling. For example, an L-band amplifier with a triple-tuned signal circuit had a nearly flat fractional bandwidth of $23 \%$, a gain of $7 \mathrm{~dB}$ and a noise figure of $0.9 \mathrm{~dB}$ at room temperature, reduced to $0.4 \mathrm{~dB}$ at $77^{\circ} \mathrm{K}$ [40]. Simpler double-tuned signal circuits may also give good results [41], and have been demonstrated at frequencies up to $18 \mathrm{GHz}$ [42]. Increases in bandwidth can also be obtained using actively compensated circuits, i.e. circuits containing multiple varactor diodes rather than multiple passive resonators [43]. However, the design trade-offs at the lower frequencies of MRI have yet to be explored.

\section{METHODS}

There are several difficulties in the construction of a parametrically amplified detector for MRI signals. Each loop must be protected against coupling to the transmitter. The circuit must localize the resonances correctly, and pump breakthrough must be prevented from triggering the decoupling. Unfortunately, useful idler and pump frequencies lie above the self-resonance of high-value air-cored inductors, making the choice of suitable frequencies difficult. Circuit losses and the varactor parameters must be such that gain may be achieved without excessive pump power. As a result, some compromises were made in the design of the initial prototype.

\subsection{Experimental circuit}

Figures $4 \mathrm{a}$ and $4 \mathrm{~b}$ show the equivalent circuit and realization of the amplified detector. The circuit was constructed on a FR-4 printed circuit board (PCB). The signal and pump inductors $L_{\mathrm{S}}$ and $L_{\mathrm{P}}$ were $190 \mathrm{~mm} \times 60 \mathrm{~mm}$ and 90 $\mathrm{mm}$ x $60 \mathrm{~mm}$ rectangular loops, respectively, with a track width of $2 \mathrm{~mm}$ and a $\mathrm{Cu}$ thickness of $85 \mu \mathrm{m}$, placed at either end of the PCB with the idler between. Other components were either non-magnetic PCB inductors or coaxial cables, or surface mount components with trace magnetism.

Decoupling was achieved using a passively switched tank filter (the capacitor $C_{\mathrm{DS}}$, the coaxial inductor $L_{\mathrm{DS}}$ and the crossed diodes $D_{\mathrm{S}}$ ) at the signal frequency $f_{\mathrm{S}}$ in the signal loop, and a fixed tank $\left(C_{\mathrm{DP}}\right.$ and $\left.L_{\mathrm{DP}}\right)$ at $f_{\mathrm{S}}$ in the pump loop. The idler was based on a small spiral PCB inductor $L_{\mathrm{I}}$ parallel to the excitation field. The signal frequency was $63.85 \mathrm{MHz}$, for ${ }^{1} \mathrm{H}$ MRI at $1.5 \mathrm{~T}$. The low self-resonant frequency of $L_{\mathrm{I}}$ forced the use of a low frequency idler $\left(f_{\mathrm{I}}=36.15 \mathrm{MHz}\right)$, so that $f_{\mathrm{P}}=$ $100 \mathrm{MHz}$. Consequently, the amplifier had a poor noise factor (estimated as $F_{\mathrm{A}} \approx 4.53$, or $6.5 \mathrm{~dB}$ ).

$C_{\mathrm{V}}$ was a silicon varactor, which had high capacitance and a high Q-factor (ZC832B; Zetex Semiconductors). To avoid a cable to a remote power supply, a $1150 \mathrm{mAh} \mathrm{Li-ion} \mathrm{battery}$ (CGA-S005E; Panasonic) was used to provide a DC bias via resistors $R$. The bias voltage was stabilized using Zener diode $D_{\text {bat }}$ fed from a resistor $R_{\text {bat }}$. Tuning of the signal, idler and pump loop was accomplished with fixed capacitors $C_{\mathrm{TS}}, C_{\mathrm{I}}$, $C_{\mathrm{T} 1 \mathrm{P}}$ and $C_{\mathrm{T} 2 \mathrm{P}}$. Capacitive matching via $\mathrm{C}_{\mathrm{MS}}$ was used to couple the output to a $50 \Omega$ load, using a bandpass filter (BPF) operating at $f_{\mathrm{S}}$ to provide protection from any currents at $f_{\mathrm{P}}$. Matching via $C_{\mathrm{MP}}$ was used to couple the pump to a signal generator, using a one-to-one balun and a high-pass filter (HPF) to minimize ground loop effects at $f_{\mathrm{S}}$.

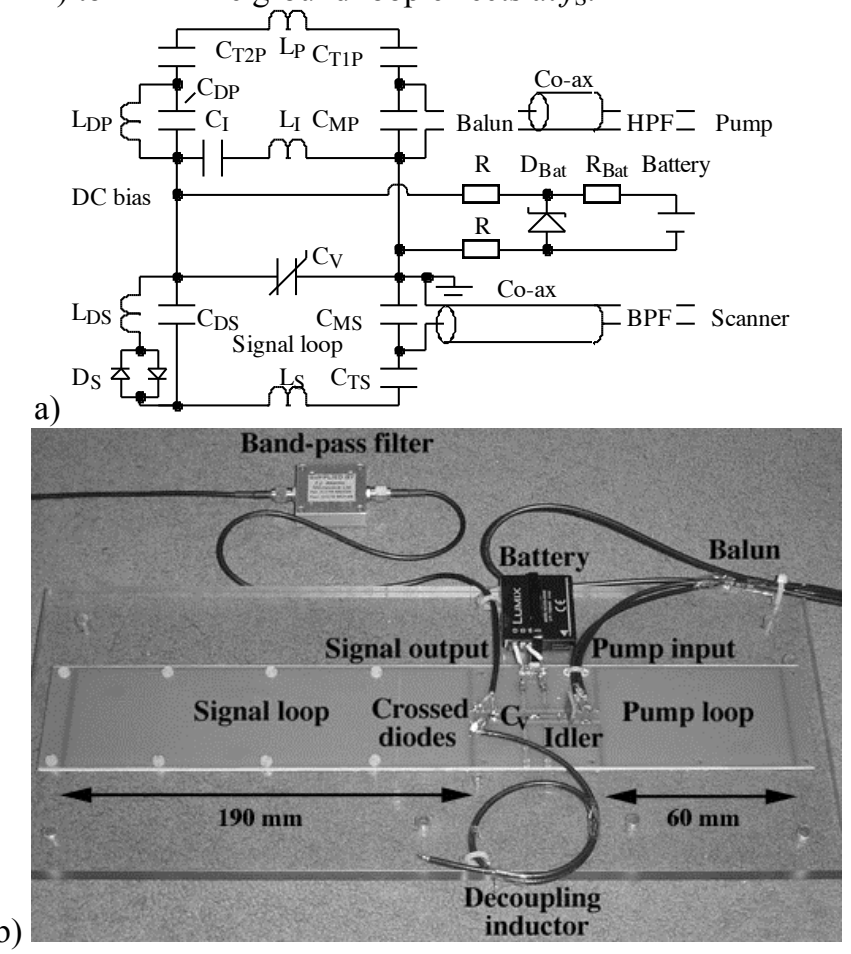

Fig. 4. a) Equivalent circuit and b) realisation of amplified detector.

\subsection{Electrical characterization}

Electrical characterization was performed using an Agilent E5061A electronic network analyzer (ENA), with an Agilent N5181A signal generator as a pump source. The amplifier was mounted in a screened enclosure, and the ENA used to optimize tuning and matching. Test voltages were injected into the signal loop via a small inductor, and the ENA used to measure the transmission $\mathrm{S}_{21}$ from the signal port.

\subsection{MR Imaging}

${ }^{1} \mathrm{H}$ MRI was carried out using a $1.5 \mathrm{~T}$ GE Signa Excite. The parametrically amplified detector was connected to an auxiliary coil input, thus placing it in series with the system 
preamplifier. Without pumping, the amplified detector acted simply as a passive coil, allowing a baseline SNR to be established. With pumping, any degradation to the SNR can then be attributed to the noise factor of the parametric amplification process. The detector was mounted on a cuboid phantom, parallel to the magnet bore. The phantom contained a solution of $3.37 \mathrm{~g} / \mathrm{L} \mathrm{NiCl} 2.6 \mathrm{H}_{2} 0$ and $2.4 \mathrm{~g} / \mathrm{L} \mathrm{NaCl}$, with $\mathrm{T} 1=$ $500-800 \mathrm{~ms}$ and T2 $=100-200 \mathrm{~ms}$. Imaging was carried using a $2 \mathrm{D}$ axial fast spoiled gradient recalled sequence, with $\mathrm{TR}=$ $100 \mathrm{~ms}, \mathrm{TE}=3.452 \mathrm{~ms}$ and a nominal flip angle of $80^{\circ}$. Multislice images were acquired in blocks of 20 using a single excitation, with a slice thickness of $5 \mathrm{~mm}, 10 \mathrm{~mm}$ between slices and $240 \mathrm{~mm}$ field of view (FOV). Images were reconstructed as a $256 \times 256$ array, using a bandwidth of $244.141 \mathrm{~Hz} /$ pixel. Each image contained a cross-section of the phantom below a source-free region. Phase encoding was in the vertical direction and frequency encoding in the horizontal. Using the auto prescan facility, suitable imaging parameters were first identified without pumping. Using manual prescan and the console display, the pump power was gradually increased, while reducing the transmitter power and the receiver gains to minimise overload. Images were then acquired while varying only the pump power and pump frequency, to obtain consistent sets of data.

\section{RESULTS}

\subsection{Varactor performance}

The performance of the varactor was measured by incorporation into a separate passive resonator and is compared with manufacturer's data in Figure 5. The bias point was then chosen as $-3.8 \mathrm{~V}$; at this voltage, $C_{0}=16 \mathrm{pF}$ and $\mathrm{d} C_{\mathrm{V}} / \mathrm{d} V=-2.5 \mathrm{pF} / \mathrm{V}$, so that $\beta=-0.156 \mathrm{~V}^{-1}$. At this point, high gains were achieved using pump powers of ca $10 \mathrm{~mW}$. However, due to losses, it was not possible to compare these powers with an estimate of $k$.

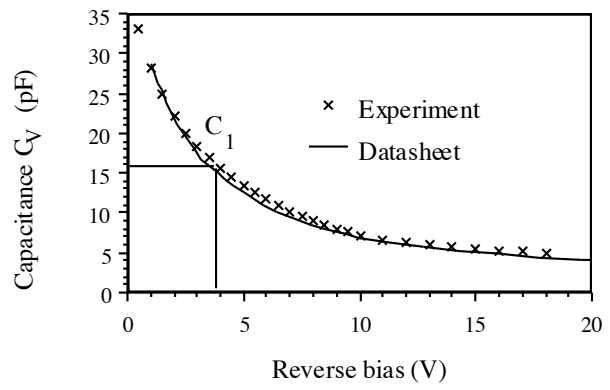

Fig. 5. Variation of varactor capacitance with reverse bias voltage.

\subsection{Amplifier gain and bandwidth}

Figure 6 shows the frequency variation of transmission $S_{21}$ through the amplifier at different pump powers. The peak transmission and Q-factor both rise rapidly as $P$ increases, and demonstrate that the parametrically amplified detector is effectively a coil with an electrically controllable Q-factor.

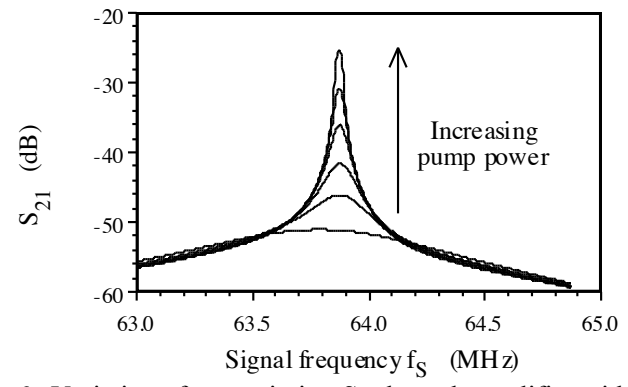

Fig. 6. Variation of transmission $S_{21}$ through amplifier with signal frequency.

Detailed calibration was then carried out, by extracting the peak amplifier gain $G_{\mathrm{A} 0}$ and the Q-factor $Q_{\mathrm{A}}$ from such data, and comparing their variations with the predictions of Section 2. The crosses in Figure 7 show the experimental variation of peak gain with normalised pump power. A maximum gain of $\approx 100$ (40 dB power gain) is shown, with a threshold of 7.5 $\mathrm{mW}$, and excellent agreement with Equation 2 is obtained.

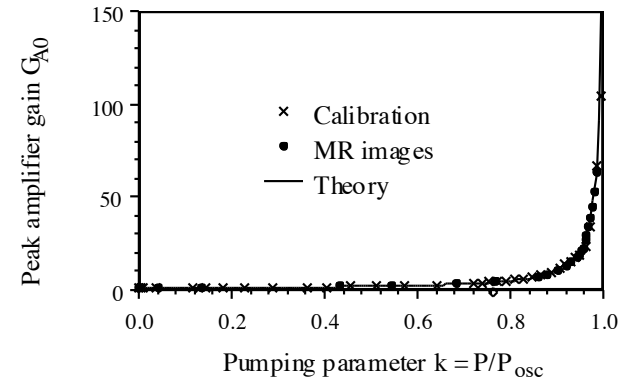

Fig. 7. Variation of peak gain with normalised pump power. Line is theory; points are experiment obtained from calibration (crosses) and MRI (circles).

The crosses in Figure 8 show the experimental variation of overall Q-factor with peak gain, superimposed on the estimate of Equation 4 and a more detailed calculation using Equation A10. At low gain, the experimental Q-factor is 60 , while at high gain it has risen to 18,000 . For the theoretical curve, $Q_{\mathrm{S}}$ determines the Q-factor at low gain, and its value was adjusted to match the value above. Once $Q_{\mathrm{s}}$ was known, the theoretical value of $Q_{\mathrm{I}}$ was adjusted (also to 60) for agreement at high gain. Excellent agreement is obtained over the whole range. As $G_{\mathrm{A} 0}$ increases, $Q$ rises smoothly from that of the passive coil to the asymptotic limit. The gain-bandwidth can be obtained from Equation 5 as $G_{\mathrm{A} 0} B=3.85 \times 10^{5} \mathrm{~Hz}$.

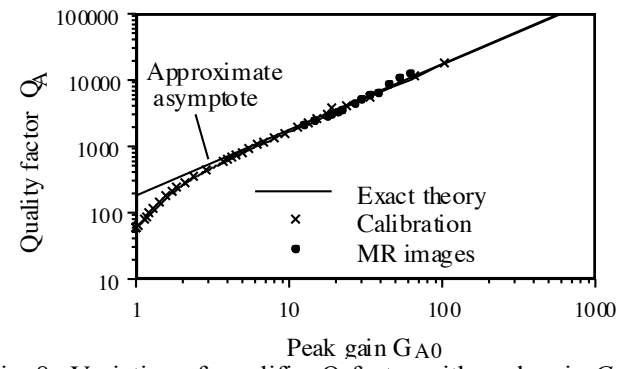

Fig. 8. Variation of amplifier Q-factor with peak gain $G_{\mathrm{A} 0}$. Line is theory, assuming $f_{\mathrm{S}}=63.85 \mathrm{MHz}, f_{\mathrm{P}}=100 \mathrm{MHz}$, and $Q_{\mathrm{S}}=Q_{\mathrm{I}}=60$; points are experiment, obtained from calibration (crosses) and MR images (circles).

\subsection{Amplifier tuning characteristics}

Tuning characteristics were obtained by varying the pump frequency, and measuring the optimum signal frequency and the gain at that frequency. Figure 9 shows the experimental 
variation of the normalised signal frequency shift $\Delta w_{\mathrm{S}}$ with the normalised pump frequency shift $\Delta w_{\mathrm{P}}=\Delta \omega_{\mathrm{P}} / \omega_{\mathrm{S} 00}$.

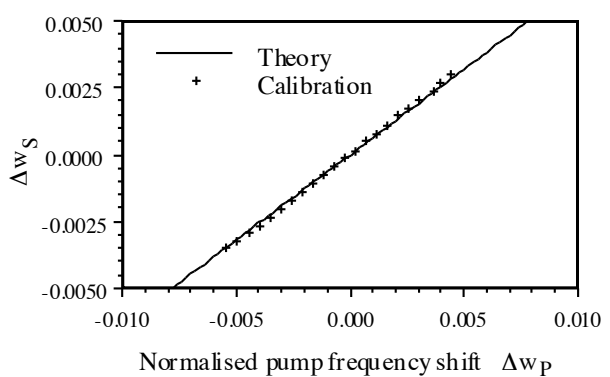

Fig. 9. Variation of normalised signal frequency shift $\Delta w_{\mathrm{S}}$ with normalised pump frequency shift $\Delta w_{\mathrm{p}}$. Line is theory, assuming $f_{\mathrm{S}}=63.85 \mathrm{MHz}, f_{\mathrm{P}}=100$ $\mathrm{MHz}$, and $Q_{\mathrm{S}}=Q_{\mathrm{I}}=60$; points are experiment.

The results are compared with the prediction of Equation 12 , for the same resonant frequencies and Q-factors as before. The experimental tuning rate is in good agreement with the theoretical prediction, estimated as $\Delta f_{\mathrm{S}}=0.6385 \Delta f_{\mathrm{P}}$, and linear tuning is obtained over a wide range.

Figure 10 shows the experimental variation of peak gain with $\Delta w_{\mathrm{P}}$, as the amplifier is tuned. The gain clearly reduces as $\Delta w_{\mathrm{P}}$ increases, following a bell-shaped curve. The results are compared with the prediction of Equation 11, for the same parameters as before, but assuming also that the pump Qfactor is $Q_{\mathrm{P}}=100$ to match with the data. Once again, good agreement is obtained. Experimentally, it was verified that the peak gain could be restored by adjustment to the pump power.

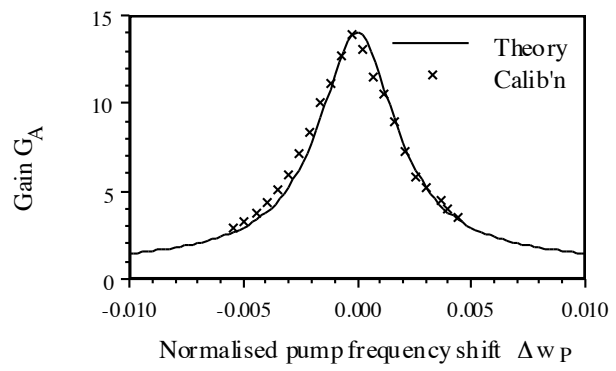

Fig. 10. Variation of peak gain $G_{\mathrm{A}}$ with normalised pump frequency shift $\Delta w_{\mathrm{P}}$. Line is theory, assuming $f_{\mathrm{S}}=63.85 \mathrm{MHz}, f_{\mathrm{P}}=100 \mathrm{MHz}, Q_{\mathrm{S}}=Q_{\mathrm{I}}=60$ and $Q_{\mathrm{P}}=100$; points are experiment.

\subsection{Amplifier loading characteristics}

Because most loads alter damping and tuning simultaneously, systematic investigation of loading was difficult. Consequently, experimental investigation of this aspect was restricted to verification that similar gains could be achieved after loading if the pump frequency and pump power were altered when an imaging specimen (a cucumber) was placed directly on the coil. This was indeed the case, but significant increases in threshold $(\mathrm{x} 2-\mathrm{x} 3)$ were observed.

\subsection{MR image gain}

Electrical calibration as compared with MR image data as follows. Figure 11 shows images of the same slice, obtained using $\mathrm{f}_{\mathrm{P}}=100.00068 \mathrm{MHz}$ and amplifier gains of a) 1, b) 20, c) 30 , d) 40 , e) 50 , and f) 65 . In each case, a cross-section of the cuboid phantom may be seen. For $G_{\mathrm{A} 0}=1$, the image brightness is low, but relatively uniform. Almost all the phantom can be seen, and the variation in brightness is symmetrical about a vertical axis just to the right of centre, falling off as expected for a rectangular coil.
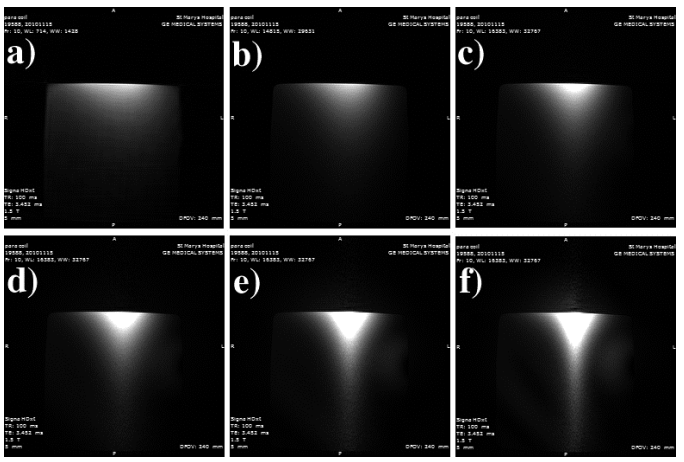

Fig. 11. Images obtained with gains of a) 1, b) 20, c) 30, d) 40, e) 50, f) 65 .

As $G_{\mathrm{A} 0}$ rises, the brightness increases and becomes more concentrated. This effect is a receiver artefact caused by restricted coil bandwidth. Dark bands also eventually appear, together with a slight increase in background noise above the phantom (a halo artifact caused by overload). Gains were extracted from images by dividing the average signal in a 10 pixel x 10 pixel region of interest (ROI) by the value without pumping. In the phase encoding direction, the gain distribution was constant for nominal gains below 30. However, as the gain rose further, some small non-uniformity appeared due to overload. The circles in the earlier Figure 7 show the variation of $G_{\mathrm{A} 0}$ with normalised pump power $P / P_{\text {osc }}$ near the top of the phantom, as extracted from image data. There is good agreement with theory and with electrical calibration data.

\subsection{Signal-to-noise ratio}

Signal-to-noise ratio (SNR) was extracted by dividing the average signal with the standard deviation in a source-free ROI of the same width and location but variable height. These values must be treated with caution. When $G_{\mathrm{A} 0} \approx 1$, the SNR may be quite poor when system gains are deliberately suppressed. As $G_{\mathrm{A} 0}$ rises, there may be an increase in SNR due to the normal effects of front-end amplification, depending on the input SNR and the noise factor and gain of downstream electronics. As $\mathrm{G}_{\mathrm{A} 0}$ rises further, there may be a reduction in $\mathrm{SNR}$, due to the noise of the parametric process. Finally, as $G_{\mathrm{A} 0}$ becomes very large, there may be a further reduction due to image distortion. Each effect has been observed in different experiments. Figure 12 shows a typical variation in which the SNR is constant at 90 for gains between 5 and 20 .

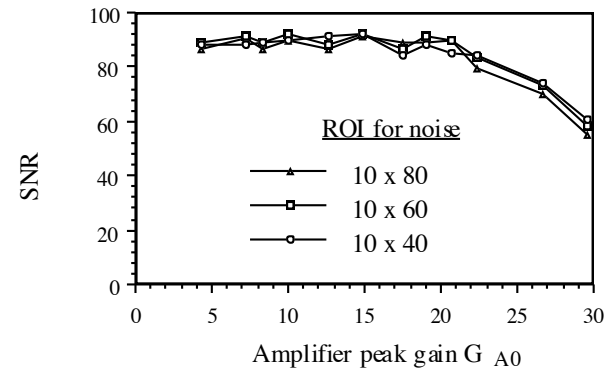

Fig 12. Variation of SNR with peak gain, for different regions of interest. For $\mathrm{G}_{\mathrm{A} 0}>20$, the SNR decreases. In principle, this reduction should allow extraction of the noise factor. However, the variation between noise ROIs suggests that any such estimate would be significantly altered by overload artefacts.

\subsection{MR image bandwidth}


$\operatorname{xxxxxx}$

Amplifier bandwidth was also correlated with image data. Figure 13 shows the horizontal variation in gain near the top of the phantom, at different pump powers. The resonant response of the detector can be seen as a variation in gain in the frequency-encoding direction. Clearly, the reduced bandwidth at high gain has a significant impact on the image, and this may have applications in deliberately limiting the FOV. The data may be converted into frequency variations of gain, by scaling with the bandwidth per pixel, and the Q-factor may then be found using the half-power bandwidth. The circles in Figure 8 show the variation of $Q$ with $G_{\mathrm{A} 0}$ extracted from image data. The results are in good agreement with calibration at low gain, but small discrepancies appear at higher gain.

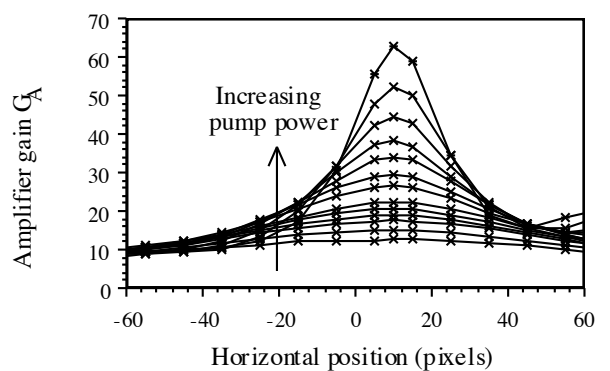

Fig. 13. Variation of image gain with position, near top of phantom.

\subsection{Image shifting}

Since the optimum signal frequency depends on the pump frequency, the FOV can be altered, by tuning $f_{\mathrm{P}}$. Figure 14 shows images with peak gains of 50 obtained using a) $f_{\mathrm{P}}=$ $100.00068 \mathrm{MHz}$ and b) $f_{\mathrm{P}}=99.98818 \mathrm{MHz}$ (so that $\Delta f_{\mathrm{P}}=12.5$ $\mathrm{kHz}$ ). The brightest region has moved to the right in Figure $14 \mathrm{~b}$, by $\approx 33$ pixels. From the tuning rate, the change in optimum signal frequency can be estimated as $\Delta f_{\mathrm{S}}=0.6385$ $\Delta f_{\mathrm{P}}$, or $7.981 \mathrm{kHz}$. This value may be converted into a shift of 32.7 pixels, in good agreement. Accompanying this shift is a reduction in Q-factor, from $\approx 8300$ to $\approx 7500$. Presumably this arises from the relatively large change in centre frequency, which is beyond the scope of linear tuning theory.

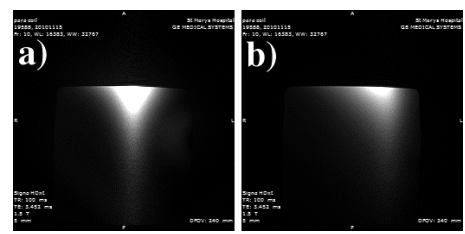

Fig. 14. ${ }^{1} \mathrm{H}$ MR images obtained at two different pump frequencies.

\section{DISCUSSION AND CONCLUSIONS}

Parametrically amplified detection of ${ }^{1} \mathrm{H}$ MR signals has been demonstrated at $1.5 \mathrm{~T}$. Substantial improvements are needed before the detector presented here will become competitive. However, we have identified the main requirements: lower noise figure and higher gain-bandwidth product, both realizable by available techniques. Clearly, our idler and pump frequencies have been too low. By placing them in the low $\mathrm{GHz}$ region, better noise figures than those of existing MR front-end amplifiers can be obtained. For simplicity we have used a single-tuned signal circuit that yielded a low gain-bandwidth product. Using double- or tripletuned circuits there is no difficulty in matching the image bandwidth. Suitable configurations are likely to involve unpackaged varactors and microstrip technology.

It is too early to identify concrete advantages for parametrically amplified detectors. However, their ability to compensate for changes in loading may have applications in balancing the response of coil arrays, both in reception and in transmission. Secondly, their narrow bandwidth might have applications in rejecting out-of-band noise or dominant signals early in the receiver chain, especially in radial image scanning or in MR spectroscopy. Thirdly, recovery times may be reduced, by modulating the $\mathrm{Q}$ factor dynamically. It is hoped that this demonstration will spark interest in reviving a lownoise amplification mechanism for improving the operation of MR detectors.

\section{APPENDIX}

The gain of the amplified detector in Figure 1 may be found as follows. For the three loops containing the varactor, Kirchhoff's voltage law gives:

$$
\begin{gathered}
\left(R_{\mathrm{SO}}+R_{\mathrm{L}}+R_{\mathrm{S}}\right) I_{\mathrm{S}}+L_{\mathrm{S}} \mathrm{d} I_{\mathrm{S}} / \mathrm{d} t+\left(1 / C_{\mathrm{S}}\right) \int I_{\mathrm{S}} \mathrm{d} t+\left(I_{\mathrm{S}}+I_{\mathrm{P}}+I_{\mathrm{I}}\right) R_{\mathrm{C}}+V_{\mathrm{C}}=V_{\mathrm{S}} \\
R_{\mathrm{I}} I_{\mathrm{I}}+L_{\mathrm{I}} \mathrm{d} I_{\mathrm{I}} / \mathrm{d} t+\left(1 / \mathrm{C}_{\mathrm{I}}\right) \int I_{\mathrm{I}} \mathrm{d} t+\left(I_{\mathrm{S}}+I_{\mathrm{P}}+I_{\mathrm{I}}\right) R_{\mathrm{C}}+V_{\mathrm{C}}=0 \\
\left(R_{\mathrm{PO}}+R_{\mathrm{P}}\right) I_{\mathrm{P}}+L_{\mathrm{P}} \mathrm{d} I_{\mathrm{P}} / \mathrm{d} t+\left(1 / \mathrm{C}_{\mathrm{P}}\right) \int I_{\mathrm{P}} \mathrm{d} t+\left(I_{\mathrm{S}}+I_{\mathrm{P}}+I_{\mathrm{I}}\right) R_{\mathrm{C}}+V_{\mathrm{C}}=V_{\mathrm{P}}
\end{gathered}
$$

Here S, I and P refer to signal, idler and pump, respectively. The response of the varactor to the voltage $V_{\mathrm{C}}$ across it is taken as the linear variation $C_{\mathrm{V}}=C_{0}\left(1+\beta V_{\mathrm{C}}\right)$, where $\beta$ is a non-linear coefficient. The varactor current is then:

$$
I_{\mathrm{S}}+I_{\mathrm{P}}+I_{\mathrm{I}}=\mathrm{d}\left(C_{\mathrm{V}} V_{\mathrm{C}}\right) / \mathrm{d} t=C_{0}\left(1+2 \beta V_{\mathrm{C}}\right) \mathrm{d} V_{\mathrm{C}} / \mathrm{d} t
$$

To solve the equations, steady-state voltages and currents are assumed in the form:

$$
\begin{aligned}
& V_{\mathrm{S}}=\left(v_{\mathrm{S}} \mathrm{e}^{\mathrm{j}_{\omega} \mathrm{s} t}+v_{\mathrm{S}} * \mathrm{e}^{-\mathrm{j}_{\omega} \mathrm{s} t}\right) / 2 ; V_{\mathrm{I}}=\left(v_{\mathrm{I}} \mathrm{e}^{\mathrm{j}_{\omega} \mathrm{I} t}+v_{\mathrm{I}} * \mathrm{e}^{-\mathrm{j}_{\omega} \mathrm{I} t}\right) / 2 \\
& V_{\mathrm{P}}=\left(v_{\mathrm{P}} \mathrm{e}^{\mathrm{j}_{\mathrm{p}} \mathrm{p} t}+v_{\mathrm{P}} \mathrm{e}^{-\mathrm{j}_{\omega} \mathrm{p} t}\right) / 2 ; I_{\mathrm{S}}=\left(i_{\mathrm{S}} \mathrm{e}^{\mathrm{j}_{\omega} \mathrm{s} t}+i_{\mathrm{S}}{ }^{*} \mathrm{e}^{-\mathrm{j}_{\omega} \mathrm{s} t}\right) / 2 \\
& I_{\mathrm{I}}=\left(i_{\mathrm{I}} \mathrm{e}^{\mathrm{j}_{\omega} \mathrm{i} t}+i_{\mathrm{I}} * \mathrm{e}^{-\mathrm{j}_{\omega} \mathrm{i}_{\omega}}\right) / 2 ; I_{\mathrm{P}}=\left(i_{\mathrm{P}} \mathrm{e}^{\mathrm{j}_{\omega} \mathrm{p} t}+i_{\mathrm{P}} * \mathrm{e}^{-\mathrm{j}_{\omega} \mathrm{p} t}\right) / 2 \\
& V_{\mathrm{C}}=\left(v_{\mathrm{CS}} \mathrm{e}^{\mathrm{j}_{\omega} \mathrm{st}}+v_{\mathrm{CS}} * \mathrm{e}^{-\mathrm{j}_{\omega} \mathrm{st}}\right) / 2+\left(v_{\mathrm{CI}} \mathrm{e}^{\mathrm{j}_{\omega}{ }_{\omega} i t}+v_{\mathrm{CI}} * \mathrm{e}^{-\mathrm{j}_{\omega}{ }_{\mathrm{i}} t}\right) / 2 \\
& +\left(v_{\mathrm{CP}} \mathrm{e}^{\mathrm{j}} \mathrm{p}_{\omega} t+v_{\mathrm{CP}} * \mathrm{e}^{-\mathrm{j}{ }_{\omega} \mathrm{p} t}\right) / 2
\end{aligned}
$$

Here “*” denotes complex conjugate. Substituting into Equations $\mathrm{A} 1$, assuming the mixing rule $\omega_{\mathrm{P}}=\omega_{\mathrm{S}}+\omega_{\mathrm{I}}$, and separately equating the coefficients of terms at $\omega_{\mathrm{P}}, \omega_{\mathrm{S}}$ and $\omega_{\mathrm{I}}$ (but neglecting other terms) yields:

$$
\begin{gathered}
\left(R_{\mathrm{S}}{ }^{\prime}+\mathrm{j} \omega_{\mathrm{S}} L_{\mathrm{S}}+1 / \mathrm{j} \omega_{\mathrm{S}} C_{\mathrm{S}}\right) i_{\mathrm{S}}+v_{\mathrm{CS}}=v_{\mathrm{S}} \\
\left(R_{\mathrm{I}}^{\prime}+\mathrm{j} \omega_{\mathrm{I}} L_{\mathrm{I}}+1 / \mathrm{j} \omega_{\mathrm{I}} C_{\mathrm{I}}\right) i_{\mathrm{I}}+v_{\mathrm{CI}}=0 \\
\left(R_{\mathrm{P}}^{\prime}+\mathrm{j} \omega_{\mathrm{P}} L_{\mathrm{P}}+1 / \mathrm{j} \omega_{\mathrm{P}} C_{\mathrm{P}}\right) i_{\mathrm{P}}+v_{\mathrm{CP}}=v_{\mathrm{P}}
\end{gathered}
$$

Here $R_{\mathrm{S}}{ }^{\prime}=R_{\mathrm{SO}}+R_{\mathrm{L}}+R_{\mathrm{S}}+R_{\mathrm{C}}, R_{\mathrm{I}}{ }^{\prime}=R_{\mathrm{I}}+R_{\mathrm{C}}$ and $R_{\mathrm{P}}{ }^{\prime}=R_{\mathrm{PO}}+$ $R_{\mathrm{P}}+R_{\mathrm{C}}$ are the resistances round the signal, idler and pump loops. Applying a similar procedure to A2 yields:

$$
\begin{gathered}
i_{\mathrm{S}}=\mathrm{j} \omega_{\mathrm{S}} C_{0}\left(v_{\mathrm{CS}}+\beta v_{\mathrm{CI}} * v_{\mathrm{CP}}\right) \\
i_{\mathrm{I}}=\mathrm{j} \omega_{\mathrm{I}} C_{0}\left(v_{\mathrm{CI}}+\beta v_{\mathrm{CS}} * v_{\mathrm{CP}}\right) \\
i_{\mathrm{P}}=\mathrm{j} \omega_{\mathrm{P}} C_{0}\left(v_{\mathrm{CP}}+\beta v_{\mathrm{CS}} v_{\mathrm{CI}}\right)
\end{gathered}
$$

In the strong pump approximation, the term $\beta v_{\mathrm{CS}} v_{\mathrm{CI}}$ is 
$\operatorname{XXXXXX}$

neglected by comparison with $v_{\mathrm{CP}}$. It is then assumed that the signal resonance and the signal may each be detuned from an initial value $\omega_{\mathrm{S} 00}$, so that $\omega_{\mathrm{S} 0}=\omega_{\mathrm{S} 00}+\Delta \omega_{\mathrm{S} 0}$ and $\omega_{\mathrm{S}}=\omega_{\mathrm{S} 00}+$ $\Delta \omega_{\mathrm{S}}$, where $\Delta \omega_{\mathrm{S} 0}$ and $\Delta \omega_{\mathrm{S}}$ are small. Similar notations are used to define deviations for the idler and pump frequencies. Re-arrangement yields $i_{\mathrm{P}}=v_{\mathrm{P}} / \gamma_{\mathrm{P}} R_{\mathrm{P}}^{\prime}$ and:

$$
\begin{gathered}
i_{\mathrm{S}}+i_{\mathrm{I}}^{*} \beta v_{\mathrm{P}} /\left(\mathrm{j} \gamma_{\mathrm{S}} \gamma_{\mathrm{P}} \omega_{\mathrm{I} 0} \omega_{\mathrm{P} 0} C_{0}^{2} R_{\mathrm{S}^{\prime}} R_{\mathrm{P}}{ }^{\prime}\right)=v_{\mathrm{S}} / \gamma_{\mathrm{S}} R_{\mathrm{S}}{ }^{\prime} \\
i_{\mathrm{I}}+i_{\mathrm{S}} * \beta v_{\mathrm{P}} /\left(\mathrm{j} \gamma_{\mathrm{I}} \gamma_{\mathrm{P}} \omega_{\mathrm{S} 0} \omega_{\mathrm{P} 0} C_{0}{ }^{2} R_{\mathrm{I}}^{\prime} R_{\mathrm{P}}{ }^{\prime}\right)=0
\end{gathered}
$$

Here $\gamma_{\mathrm{S}} \approx 1+\mathrm{j} \delta_{\mathrm{S}}, \gamma_{\mathrm{I}} \approx 1+\mathrm{j} \delta_{\mathrm{I}}$ and $\gamma_{\mathrm{P}} \approx 1+\mathrm{j} \delta_{\mathrm{P}}$ are filter functions for the three loops, and $\delta_{\mathrm{S}}, \delta_{\mathrm{I}}$ and $d_{\mathrm{P}}$ are detuning terms, given by:

$$
\begin{gathered}
\delta_{\mathrm{S}}=2 Q_{\mathrm{S}}\left(\Delta \omega_{\mathrm{S}}-\Delta \omega_{\mathrm{S} 0}\right) / \omega_{\mathrm{S} 00} \\
\delta_{\mathrm{I}}=2 Q_{\mathrm{I}}\left(\Delta \omega_{\mathrm{P}}-\Delta \omega_{\mathrm{S}}-\Delta \omega_{\mathrm{I} 0}\right) / \omega_{\mathrm{I} 00} \\
\delta_{\mathrm{P}}=2 Q_{\mathrm{P}}\left(\Delta \omega_{\mathrm{P}}-\Delta \omega_{\mathrm{P} 0}\right) / \omega_{\mathrm{P} 00}
\end{gathered}
$$

Here $\omega_{\mathrm{S} 0}=\sqrt{ }\left\{\left(1 / C_{\mathrm{S}}+1 / C_{0}\right) / L_{\mathrm{S}}\right\}, \omega_{\mathrm{I} 0}=\sqrt{ }\left\{\left(1 / C_{\mathrm{I}}+1 / C_{0}\right) / L_{\mathrm{I}}\right\}$ and $\omega_{\mathrm{P} 0}=\sqrt{ }\left\{\left(1 / C_{\mathrm{P}}+1 / C_{0}\right) / L_{\mathrm{P}}\right\}$ are the angular resonant frequencies of the three loops, and $Q_{\mathrm{S}}=\omega_{\mathrm{S} 0} L_{\mathrm{S}} / R_{\mathrm{S}}{ }^{\prime}, Q_{\mathrm{I}}=\omega_{\mathrm{I} 0} L_{\mathrm{I}} / R_{\mathrm{I}}{ }^{\prime}$ and $Q_{\mathrm{P}}=$ $\omega_{\mathrm{P} 0} L_{\mathrm{P}} / R_{\mathrm{P}}{ }^{\prime}$ are the corresponding Q-factors.

Equations A6 may be solved for the gain $G=v_{\mathrm{L}} / v_{\mathrm{S}}$, where $v_{\mathrm{L}}=i_{\mathrm{S}} R_{\mathrm{L}}$ is the load voltage. If the system is matched so that $R_{\mathrm{L}} / R_{\mathrm{S}}{ }^{\prime} \approx 1 / 2$, the overall gain is $G \approx G_{\mathrm{C}} G_{\mathrm{A}}$, where $G_{\mathrm{C}}$ and $G_{\mathrm{A}}$ are the separate gains of the coil and amplifier, given by:

$$
G_{\mathrm{C}}=1 /\left(2 \gamma_{\mathrm{S}}\right) ; G_{\mathrm{A}}=1 /\left\{1-k /\left(\gamma_{\mathrm{S}} \gamma_{\mathrm{I}}^{*} \gamma_{\mathrm{P}} \gamma_{\mathrm{P}}{ }^{*}\right)\right\}
$$

Here $k$ is the pumping parameter, given by:

$$
k \approx \beta^{2} v_{\mathrm{P}} v_{\mathrm{P}}^{*} /\left(\omega_{\mathrm{S} 0} \omega_{\mathrm{I} 0} \omega_{\mathrm{P} 0}^{2} C_{0}^{4} R_{\mathrm{S}} R_{\mathrm{I}}^{\prime} R_{\mathrm{P}}^{\prime 2}\right)
$$

The gain $G_{\mathrm{C}}$ and $G_{\mathrm{A}}$ may then be approximated as:

$$
\begin{gathered}
G_{\mathrm{C}}=1 /\left\{2\left(1+\mathrm{j} \delta_{\mathrm{S}}\right)\right\} \\
G_{\mathrm{A}}=\left\{1+\delta_{\mathrm{P}}{ }^{2}+\mathrm{j}\left(\delta_{\mathrm{S}}-\delta_{\mathrm{I}}\right)\right\} /\left\{1+\delta_{\mathrm{P}}{ }^{2}-k+\mathrm{j}\left(\delta_{\mathrm{S}}-\delta_{\mathrm{I}}\right)\right\}
\end{gathered}
$$

$G_{\mathrm{A}}$ can clearly be much larger and faster varying than $G_{\mathrm{C}}$ when $k$ approaches $1+\delta_{\mathrm{P}}{ }^{2}$, so that the pumping parameter largely controls the gain and bandwidth. For high gain, the numerator may be approximated as unity, so that:

$$
G_{\mathrm{A}} \approx 1 /\left\{\left(1+\delta_{\mathrm{P}}^{2}-k\right)+\mathrm{j}\left(\delta_{\mathrm{S}}-\delta_{\mathrm{I}}\right)\right\}
$$

Equations A8 - A11 may then be used to find the amplifier gain under various conditions. If $\delta_{\mathrm{S}}, \delta_{\mathrm{I}}$ and $\delta_{\mathrm{P}}$ are all zero, we obtain the synchronous gain $G_{\mathrm{A} 0}$, given by:

$$
G_{\mathrm{A} 0} \approx 1 /(1-k)
$$

In other cases, $G_{\mathrm{A}}$ may be found by combining A7 with A11.

\section{REFERENCES}

[1] D.I. Hoult, P.C. Lauterbur, "The sensitivity of the zeugmatographic experiment involving human samples" J. Magn. Reson. Vol. 34, pp. 425-433, May 1979.

[2] C.E. Hayes, L. Axel, "Noise performance of surface coils for magnetic resonance imaging at $1.5 \mathrm{~T}$ " Med. Phys. Vol. 12, pp. 604-607, Sept.
1985.

[3] A. Simmons, P.S. Tofts, G.J. Barker, S.R. Arridge, "Sources of nonuniformity in spin echo images" Magn. Reson. Med. Vol. 32, pp. 121-128, July 1994.

[4] G.N. Holland, J.R. MacFall, "An overview of digital spectrometers for MR imaging" J. Magn. Reson. Imag. Vol. 2, pp. 241-246, March/April1992.

[5] J.M. Manley, H.E. Rowe, "Some general properties of nonlinear elements - Part I. General energy relations" Proc. IRE Vol. 44, pp. 904913, July 1956.

[6] W.W. Mumford, "Some notes on the history of parametric transducers" Proc. IRE Vol. 48, p. 848-853, May 1960.

[7] V.D. Landon, "The use of ferrite-cored coils as converters, amplifiers and oscillators" RCA Rev. Vol. 10, pp. 387-396, Sept. 1949.

[8] A. Van der Ziel, "On the mixing properties of nonlinear condensers" J. Appl. Phys. Vol. 19, p. 999-1006, Nov. 1948

[9] E.D. Reed, "The variable-capacitance parametric amplifier" IRE Trans. Electron Dev. Vol. 6, pp. 216-224, April 1959.

[10] B.J. Robinson, "Theory of variable capacitance parametric amplifiers" IEE Proc. Vol. 109C, pp. 198-208, Nov. 1961.

[11] G.L. Matthaei, "Experimental verification of the phase relationships in parametric amplifiers" IEEE Trans. Micr. Theor. Tech. Vol. MTT-12, pp. 365-367, May 1964

[12] H. Heffner, K. Kotzebue, "Experimental characteristics of a microwave parametric amplifier using a semiconductor diode" Proc. IRE Vol. 46, p. 1301, June 1958

[13] C.S. Aitchison, R. Davies, P.J. Gibson, "A simple diode parametric amplifier design for use at S, C and X band" IEEE Trans. Micr. Theor. Tech. Vol. MTT-15, 22-31, Jan. 1967

[14] J. Whelehan, E. Moley, "A low-noise K-band nondegenerate parametric amplifier" Proc. IEEE Vol. 52, pp. 209-210, Aug. 1964.

[15] C.E.W. Barnes, W.J. Bertram, M.J. Cowan, "Low noise wide band Lband parametric amplifier" Tech. Dig. IEEE Int. Solid State Circuits Conf., Feb. 24-25 1964, pp. 24-25

[16] J.T. De Jager, "Parametric amplifiers for radio astronomy" Solid State Elect. Vol. 4, pp. 266-270, 1962.

[17] M. Uenohara, J.P. Elward, "Parametric amplifiers for high sensitivity receivers" IEEE Trans. Antennas Propag. Vol. AP-12, pp. 939-947, Dec. 1964

[18] R.A. Baumgartner, R.L. Byer "Optical parametric amplification" IEEE J. Quant. Elect. Vol. QE-15, pp. 432-444, June 1979.

[19] J. Hansryd, P.A. Andrekson, M. Westlund, J. Li, P.-O. Hedekvist, "Fiber-based optical parametric amplifiers and their applications" IEEE J. Sel. Top. Quant. Elect. Vol. 8, pp. 506-520, May/June 2002.

[20] B. Yurke, P.G. Kaminsky, R.E. Miller, E.A. Whittaker, A.D. Smith, A.H. Silver, R.W. Simon "Observation of $4.2 \mathrm{~K}$ equilibrium noise squeezing via a Josephson parametric amplifier" Phys. Rev. Lett. Vol. 60, pp. 764-767, Feb. 1988.

[21] D. Rugar, P. Grutter, "Mechanical parametric amplification and thermomechanical noise squeezing" Phys. Rev. Lett. Vol. 67, pp. 699702, Aug. 1991

[22] W.M. Dougherty, K.J. Bruland, J.L. Garbini, J.A. Sidles, "Detection of AC magnetic signals by parametric mode coupling in a mechanical oscillator" Meas. Sci. Tech. Vol. 7, pp. 1733-1739, Dec. 1996.

[23] R.R.A.Syms, I.R. Young, L.Solymar, "Three-frequency parametric amplification of magneto-inductive ring resonators" Metamaterials Vol. 2, pp. 122-134, March 2008.

[24] A. Santic "Low frequency parametric amplifier for small voltage measurements" IEEE Trans. Instr. Meas. Vol. 23, pp. 8-14, March 1974.

[25] T.C. Hollocher, W.H. From, N.S. Bromberg, "Use of a parametric amplifier in electron spin resonance spectrometer design" Phys. Med. Biol. Vol. 9, pp. 65-72, Jan. 1964.

[26] J.P. Raskin, "A novel parametric-effect MEMS amplifier" J. Microelectromech. Syst, Vol. 9, pp. 528-537, Dec. 2000.

[27] M. Zalalutdinov, A. Olkhovets, A. Zehnder, B. Ilic, D. Czaplewski, H.G. Craighead, J.M. Parpia, "Optically pumped parametric amplification for micromechanical oscillators” Appl. Phys. Lett. Vol. 78, pp. 3142-3144, May 2001.

[28] M.J. Thompson, D.A. Horsley "Parametrically amplified z-axis Lorentz force magnetometer" J. Microelectromech. Syst. Vol. 20, pp. 702-210, June 2011.

[29] Z.X. Hu, B.J. Gallagher, J.S. Burdess, C.P. Fell, K. Townsend, "A parametrically amplified MEMS rate gyroscope" Sensors and Actuators A Vol. 167, pp. 249-260, June 2011.

[30] E.W. Sard, "Analysis of a negative conductance amplifier operated with 
XXXXXX

a non-ideal circulator" IRE Trans. Micr. Theory Tech. Vol. MTT-7, pp. 288-294, April 1959.

[31] H. Heffner, G. Wade "Gain, bandwidth and noise characteristics of a variable parameter amplifier" J. Appl. Phys. Vol. 29, pp. 132-1331, Sept. 1958.

[32] C.S. Aitchison, B.L. Humphreys, E.L. Neufeld, "The overall noise figure of diode parametric amplifier systems" Proc. IEE Vol. 110, pp. 348-352, Feb. 1963.

[33] A.S. Wong, C.S. Aitchison, "Hybrid parametric amplifier with a noise temperature of 18 K" Electr. Lett. Vol. 12, pp. 687-688, Dec. 1976.

[34] D.F. Doty, G. Entzminger, J. Kulkarni, K. Pamarthy, J.P. Staab, "RF coil technology for small animal MRI" NMR Biomed. Vol. 20, pp. 304-325, May 2007.

[35] L.E. Dickens, "A millimetre-wave pumped X-band uncooled parametric amplifier” Proc IEEE Vol. 60, pp. 328-329, March 1972.

[36] J.C. Sadler, J.R. Wells, "Helium-cooled X-band parametric amplifier" Proc. IEEE Vol. 52, 1268-1269, Oct. 1964.

[37] K. Garbrecht, "Noise limitation in helium-cooled parametric amplifiers" Radio and Electronic Engineer Vol. 31, pp. 217-224, April. 1966.

[38] E.S. Kuh, M. Fukada, "Optimum synthesis of wide-band parametric amplifiers and converters" IRE Trans. Circuit Theory Vol. CT-8, pp. 410-415, Dec. 1961.

[39] G.L. Matthaei, "A study of the optimum design of wide-band parametric amplifiers and up-converters" IRE Trans. Micr. Theory Tech. Vol. MTT-9, pp. 23-38, Jan. 1961.

[40] J.T. DeJager, "Maximum bandwidth performance of a non-degenerate parametric amplifier with a single-tuned idler circuit" IEEE Trans. Micr. Theory Tech. Vol. MTT-12, pp. 459-467, July 1964.

[41] W.P. Connors "Maximally flat bandwidth of a nondegenerate parametric amplifier with a double tuned signal circuit and a single tuned idler circuit" IEEE Trans. Micr. Theory Tech. Vol. MTT-13, pp. 251-252, March 1965.

[42] Y. Kinoshita, M. Maeda, “An $18 \mathrm{GHz}$ double-tuned parametric amplifier" IEEE Trans. Micr. Theory Tech. Vol. MTT-18, pp. 11141119, Dec. 1970.

[43] W.S. Jones, F.J. Hyde "Two-diode bandpass parametric amplifier. Proc. IEE Vol. 114, pp. 1365-1372, Oct. 1967.

Richard Syms (SM 2002) is Professor of Microsystems Technology, EEE Dept., Imperial College London. He has published over 200 papers on holography, guided waves, metamaterials and MEMS. He is a Fellow of the Royal Academy of Engineering, a Fellow of the Institute of Electrical Engineers and a Fellow of the Institute of Physics.

Timmy Floume is a Research Associate in the EEE Dept., Imperial College London. He obtained a BSc in Physics and Chemistry from Paristech in 2001, a MSc in Electrical Engineering from Pierre and Marie Curie U. in 2001, and a PhD from Imperial College in 2008. His interests lie in biomedical instrumentation, including gamma cameras, tissue thermal interactions, optical spectroscopy, MRI coils and metamaterials.

Ian Young is Senior Research Fellow, EEE Dept., Imperial College London. He has published over 300 papers on MRI. His current interests are in-vivo MRI and MR-guided surgical robots. He is a Fellow of the Royal Society and a Fellow of the Royal Academy of Engineering, and winner of the Gold Medal of SMRM and the Sir Frank Whittle Prize.

Laszlo Solymar is Senior Research Fellow, EEE Dept., Imperial College London. Prior to that, he was Professor of Applied Electromagnetism in the Dept. of Engineering Science, Oxford University, UK. He has published extensively in communications, EM theory, photorefractives, holography, superconductivity, travelling wave tubes and antenna arrays. He is a Fellow of the Royal Society and a Fellow of the Institute of Electrical Engineers.

Marc Rea is a Clinical Scientist/Postgraduate researcher at St. Mary's Hospital, London. He obtained his PhD from Imperial College in 2010, on MR-compatible systems for prostate biopsy. His research interests include medical robotics, device tracking, and high-intensity focused ultrasound. 